\title{
Polarity Probing Two-Photon Fluorophores Based on [2.2]Paracyclophane
}

\author{
Han Young Woo. ${ }^{\dagger}$ Dmitry Korystov, ${ }^{\dagger}$ Youngeup Jin. ${ }^{+}$and Hongsuk Suh ${ }^{\ddagger}$ \\ Department of Nanomaterials Engineering (BK21), Pusan National University, Miryang 627-706, Korea \\ "E-mail: hywoo@ptsan.ac.kr \\ "Institure for Polymers and Organic Solids, University of California, Santa Barbara, California 93106, USA \\ ${ }^{*}$ Department of Chemistry and Chemistry Institute for Functional Materials, Ptisan National University, Busan 609-735, Korea \\ Received Angust 13, 2007
}

\begin{abstract}
$\Lambda$ series of tetra donor substituted [2.2]paracyclophane-based two-photon absorption (TP $\Lambda$ ) fluorophores were synthesized in neutral and cationic forms. The imaging activity of overall set of fluorophores was studied by the two-photon induced fluorescence (TPIF) method in a range of solvents. We also measured a clear progression toward a longer photoluminescence lifetime with increasing solvent polarity (intrinsic photoluminescence lifetime, $\tau_{1}: \sim 2 \mathrm{~ns}$ in toluene $\rightarrow 12-16 \mathrm{~ns}$ in water). The paracyclophane fluorophores with this unique property can be utilized as an optical polarity probe for the biomolecular substrates. The combined measurement of the two-photon fluorescence microscopy (TPM) cell image and TPIF lifetime can give us a better understanding of the biological processes and local environments in the cells.
\end{abstract}

Key Words : Two-photon absorption, Bioimaging, Two-photon fluorophore, Paracyclophane, Fluorescent label

\section{Introduction}

Since the two-photon absorption (TPA) phenomenon was theoretically predicted by M. Göppert-Mayer in 1931 and experimentally demonstrated in the $1960 \mathrm{~s},{ }^{1.2}$ TPA and twophoton induced fluorescence (TPIF) materials have received considerable attention. ${ }^{3}$ Among its various potential applications, the two-photon fluorescence microscopy (TPM) provides the best non-invasive imaging means for numerous biological systems. ${ }^{4,5}$ Fluorescent molecular tags, which are an essential consideration for TPM biological imaging, have been under substantial examination. Extensive studies on the molecular structure for efficient TPA chromophores reveal important design guidelines created to obtain high $\eta \delta(\eta$ is the fluorescence quantum yield and $\delta$ is the TPA cross section), which determines TPM imaging performance. ${ }^{6.7}$ However, most studies have been devoted to TPA properties in organic solvents. There are very limited reports on the solvent effects on TPA, the behavior in aqueous solution and molecular design for the water-soluble TPA fluorophores which are necessary for TPM biological imaging. ${ }^{8.9}$

Currently, most of the fluorophores being used for TPM are those which are developed for one-photon excitation. Therefore, they have relatively small values of $\eta \delta$, less than $\sim 50 \mathrm{GM} .{ }^{10}$ Recent molecular design guidelines created to obtain high TPA suggested how to obtain $\delta$ larger than 1000 $\mathrm{GM}^{6.7}$ One approach is a quasi-linear $\mathrm{D}-\pi$-D (or $\mathrm{D}-\pi-\mathrm{A}$ or $\mathrm{A}-\pi$-A) structure to induce strong intramolecular charge transfer (ICT) upon excitation, where D is e-donor, A is eacceptor and $\pi$ is a $\pi$-conjugated bridge. However, in polar aqueous medium required for biological samples, a strong ICT often leads to reduced $\eta$ and lower overall $\eta \delta$, indicating that maximizing the charge transfer character of the excited state is not necessarily a useful design strategy in water. ${ }^{8}$ Optical perturbation by water is quite different with respect to those by organic ones due to high polarity and specific solvent interaction such as hydrogen bonding. It suggests that a different approach should be considered for the optimized TPM-tags in water.

[2.2]Paracyclophane $(\mathrm{pCp})$-based TPA fluorophores are of interest due to their unique molecular structure and optical properties. They may be viewed as well-defined cofacial chromophore pairs with through-space electronic delocalization, ${ }^{11.12}$ which have been studied to mimic excimer and/or electronic coupling between optical units in a multi-chromophores system. ${ }^{13}$ Hong et al. investigated the paracyclophane platform for designing water-soluble optical reporters with decreased sensitivity to optical perturbations brought about by aggregation. ${ }^{14}$ The characteristics of paracyclophane bichromophores derive mainly from two states: the 'chromophore state' characterized by 'through-bond' (TB) delocalization along the parent chromophores and the 'phane state' from 'through-space' (TS) delocalization across the paracyclophane core. A unique structure with TB and TS delocalization shows a clear solvent dependence of PL lifetime due to participation of the forbidden TS state in the description of the emitting state..$^{14,15}$ This unique property of the paracyclophane framework can be utilized as an optical polarity probe for the biomolecular substrates.

In this contribution, we report the synthesis, linear and nonlinear optical spectroscopic studies of a series of $\mathrm{pCp}$ based TPA fluorophores. We also provide a comparison of photophysical properties of water-soluble fluorophores and their organic-soluble counterparts in a range of solvents. They have the same electronic conjugation with different terminal end groups which determine whether the molecule is neutral ( $\mathbf{N}$ series), and soluble in organic solvents, or cationic ( $\mathbf{C}$ series), and soluble in water. The overall set of compounds series allows for the examination of the solvent influence on linear and nonlinear optical properties, provid- 
ing insights into the local environmental effects on the TPM signals. The environmental dependence of the optical properties for the $\mathrm{xp}$ fluorophores is discussed in terms of utilizing them as optical probes for substrates in biological samples.

\section{Results and Discussion}

Synthesis. A series of tetra donor substituted $p \mathrm{Cp}$-based TPA fluorophores were synthesized in neutral and ionic forms. Different substituents were chosen to modulate the electronic conjugation and the donor strength of the nitrogen groups and to allow the molecules to be neutral or charged. The schematic synthetic routes and the molecular structures of the paracyclophane fluorophores are presented in Schemes 1 and 2. The synthesis of paracyclophane core involves tetrabromomethylation of [2.2]paracyclophane under ultrasonic condition, followed by treatment with triethylphosphite. $^{16}$
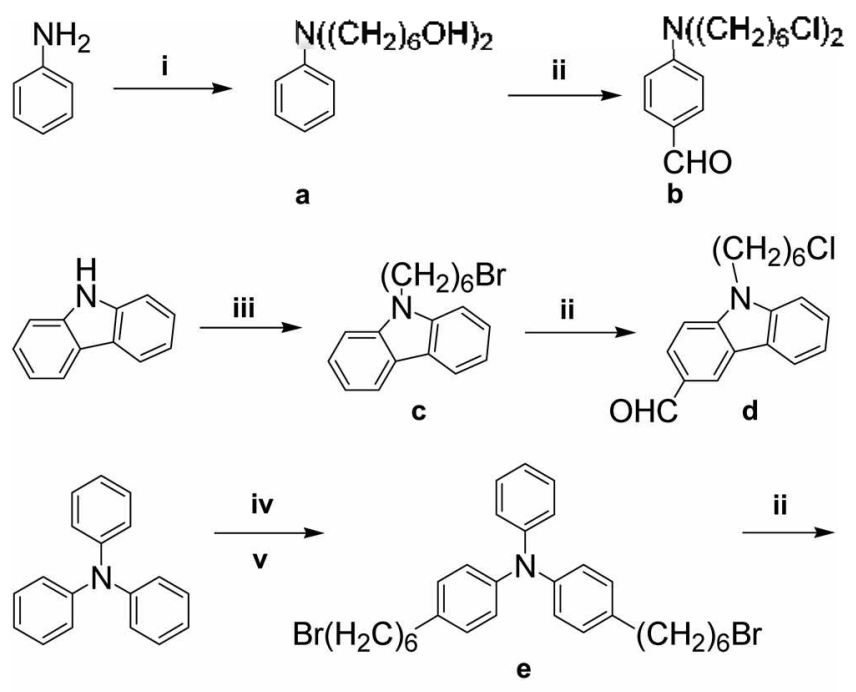<smiles>O=Cc1ccc(N(c2ccc(CCCl)cc2)c2ccc(CCCl)cc2)cc1</smiles>

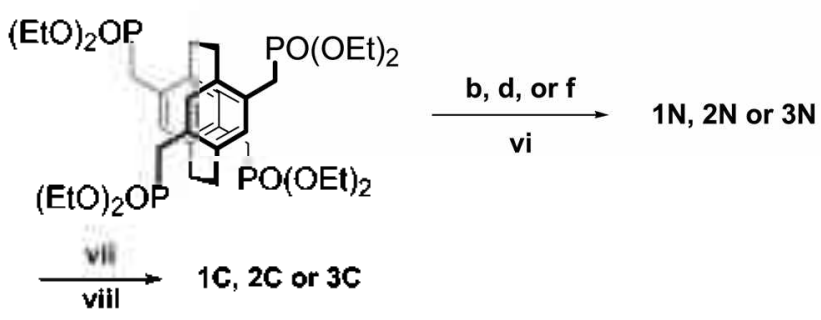

Scheme 1. Synthetic routes to neutral-and cationic paracyclophane fluorophores. Reagents and conditions: (i) $\mathrm{HO}\left(\mathrm{CH}_{2}\right)_{6} \mathrm{Cl}, \mathrm{K}_{2} \mathrm{CO}_{3}, n-$ butanol; (ii) $\mathrm{POCl}_{3}, \mathrm{DMF}$; (iii) $\mathrm{NaH}, \mathrm{Br}\left(\mathrm{CH}_{2}\right)_{6} \mathrm{Br}$, THF; (iv) Nbromosuccinimide, $\mathrm{CH}_{2} \mathrm{Cl} ;$ (v) $\mathrm{Br}\left(\mathrm{CH}_{2}\right)_{6} \mathrm{Br}, t-\mathrm{BuLi}, \mathrm{THF},-78^{\circ} \mathrm{C}$ $\rightarrow \mathrm{RT}$; (vi) $t$-BuOK, THF, $0^{\circ} \mathrm{C}$; (vii) Nal, acctone $/ \mathrm{CH}_{2} \mathrm{Cl}_{2}$; (viii) $\mathrm{NMc}, \mathrm{THF} / \mathrm{H}_{2} \mathrm{O}$.
In the first example, alkylation of aniline ${ }^{17}$ with 6-chloro1-hexanol in $n$-butanol yielded N,N-bis(6-hydroxyhexyl)aniline (a) in $70 \%$ yield. The successive Vilsmeier formylation with phosphorous oxychloride in DMF introduced aldehyde functionality, affording N,N-bis 6 -chlorohexyl-4amino)benzaldehyde (b) in light yellow oil. In the case of carbazole-containing aldehyde (d), the 9-position of carbazole was alkylated with 1,6-dibromohexane using $\mathrm{NaH}$ in dry THF under reflux conditions. The resulting $\mathrm{c}$ was formylated in the same way mentioned above. For the synthesis of triphenylamine donor (f), triphenylamine was brominated with N-bromosuccinimide in dichloromethane ${ }^{18}$ and the successive lithiation/alkylation with $t$-BuLi and excess 1,6-dibromohexane yielded e in $63 \%$ yield. Attempts to use $n-\mathrm{BuLi}$ in the lithium-halogen exchange procedure were proved to be unsuccessful, and led to a mixture of products substituted by bromobutyl or the undesired butyl group. To prevent intermolecular coupling reactions, a large excess ( 10 eq.) of 1,6-dibromohexane was added. Aldehyde functionality was easily introduced by Vilsmeier formylation to give the structure $\mathrm{f}$ in $78 \%$ yield.

Four-fold Homer-Emmons Wittig coupling between 4,7, 12,15-tetra(diethylphosphonatemethyl)-[2.2]paracyclophane and excess $\mathbf{b}, \mathbf{d}$ or $\mathbf{f}$ using potassium tert-butoxide in THF at $0^{\circ} \mathrm{C}$ gave $1 \mathrm{~N}, 2 \mathrm{~N}$ and $\mathbf{3 N}$, respectively. The reaction temperature was kept around $0^{\circ} \mathrm{C}$ in order to remove the possibility of halide elimination during the reaction. After silica gel column purification, the pure $1 \mathrm{~N}-3 \mathrm{~N}$ were obtained in yields close to $60 \%$. In the case of iodo functionality, for instance, the coupling between N,N-bis(6'-jodohexyl-4-amino)benzaldehyde and the $\mathrm{pCp}$ tetraphosphonate, $\mathrm{ca}$. 15-20\% of the terminal jodo group was eliminated during Wittig coupling. ${ }^{19}$ A Finkelstein-type reaction of $\mathbf{1 N}-\mathbf{3 N}$ with sodjum jodide exchanges the terminal chloro group into the jodo functionality in $70-80 \%$ yield. In ${ }^{1} \mathrm{H}-\mathrm{NMR}$ spectra, the methylene hydrogen peak around $3.5 \mathrm{ppm}(\mathrm{t}, J=6.6 \mathrm{~Hz})$ next to chloro functionality disappeared and a new line appeared around $3.2 \mathrm{ppm}(\mathrm{t}, J=7 \mathrm{~Hz})$ originating from those next to the jodo functional group. Formation of the final water-soluble $\mathrm{pCp}$ chromophores $(\mathbf{1 C - 3 C})$ was easily achieved via quatemization with a large excess of trimethylamine in the mixed solvent of THF and water. After addition of trimethylamine, the insoluble solid forms gradually as the reaction proceeds, which means the ionic units are formed via quatemization. To ensure that complete quatemization is achieved, it is recommended to re-dissolve the precipitated compounds by adding water and to add an excess of trimethylamine for further reaction. Removal of unreacted trimethylamine does not impose any problem because of its low boiling point. The proton resonance was observed around $3.3 \mathrm{ppm}(72 \mathrm{H})$ which originates from $-\mathrm{N}^{+}\left(\mathrm{CH}_{3}\right)_{3} \mathrm{I}^{-}$ for $4,7,12,15$-tetra[N,N-bis $\left(6^{\prime \prime}-(\mathrm{N}, \mathrm{N}, \mathrm{N}\right.$-trimethylammonium)hexy])-4'-aminostyry]]-[2.2]paracyclophane octaiodide (1C). The $\mathrm{m} / \mathrm{z}$ peaks (in Mass analysis) correspond to $\mathrm{M}^{2+}$ $2 \mathrm{I}$ at 1287.6 and $\mathrm{M}^{3+}-3 \mathrm{I}$ at 816 .I were also measured for $\mathbf{1 C}$. The final jonic $\mathrm{pCp}$ chromophores were purified by dissolving them in a small amount of hot methanol and re- 


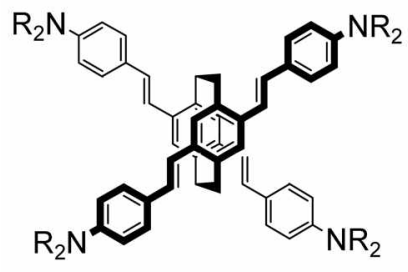

1

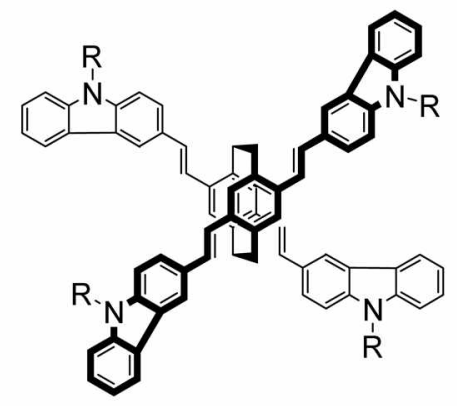

2

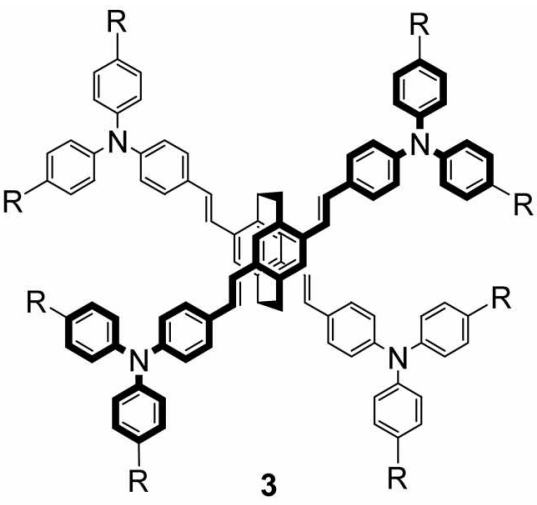

$\mathbf{N}: \mathbf{R}=\left(\mathrm{CH}_{2}\right)_{6} \mathrm{Cl}$

$\mathrm{C}: \mathrm{R}=\left(\mathrm{CH}_{2}\right)_{6} \mathbf{N}^{+}\left(\mathrm{CH}_{3}\right)_{3} \mathbf{I}^{-}$

Scheme 2. Molecular structures of neutral- and cationic paracyclophane fluorophores.

precipitating into diethyl ether, affording the pure $1 \mathrm{C}-3 \mathrm{C}$ in $85-90 \%$ yields. Both neutral- and ionic pCp compounds show the formation of the characteristic stilbene framework, which is confirmed by two doublets around 6.7-7.2 $\mathrm{ppm}(J=$ $14-16 \mathrm{~Hz}$ ) in 'H-NMR spectra.

Linear absorption and photoluminescence spectroscopy. Table 1 summarizes the absorption and photoluminescence (PL) data in several solvents of different polarity. Figure 1 shows UV/vis and PL spectra of $1 \mathbf{N}$ in toluene and $1 \mathrm{C}$ in water. The $\mathrm{pCp}$ structure can be considered as a through-space dimeric form with cofacial contact between two monomeric $\alpha, \omega$-distyrylbenzene (DSB) units via the $\mathrm{pCp}$ core. Since the effective molecular overlap between two parent monomeric DSB chromophores is possible, excitation leads to full delocalization within the entire molecule via the $\mathrm{pCp}$ core. The through-space delocalization in the molecules built around the $[2.2] \mathrm{pCp}$ skeleton has been extensively studied in previous works. ${ }^{11.12 .16 .20}$ Relative to the corresponding monomeric DSB, the red-shifted absorption and PL for the $\mathrm{pCp}$ chromophores imply an increased effective conjugation via through-space delocalization. The absorption maximum $\left(\lambda_{\mathrm{abs}}\right)$ and the PL maximum $\left(\lambda_{\mathrm{T} L}\right)$ were measured at $409 \mathrm{~nm}$ and $449 \mathrm{~nm}$ in toluene for the monomeric DSB, 1,4-bis(4'-(N,N-bis(6"-iodohexyl)armino)styryl)benzene. ${ }^{8 c}$ Note that the absorption maximum of the corresponding dimeric $\mathrm{pCp}$ compound $\mathbf{1 N}$ is red-shifted by $25 \mathrm{~nm}$ relative to the monomeric DSB. The situation in the emission is more pronounced, red-shifted by $37 \mathrm{~nm}$. In addition, $\lambda_{\text {ats }}$ and $\lambda_{\mathrm{pL}}$ for $1 \mathrm{~N}$ in toluene are similar to those reported for 4,7,12,15-tetra(4-dihexylaminostyry])-[2.2]paracyclophane, which indicates negligible perturbation on the electronic structure by the terminal halo functionalities. ${ }^{20}$

The PL spectrum of $1 \mathrm{~N}$ shows a structured emission with the maximum at $486 \mathrm{~nm}$ in toluene. As solvent polarity increases, the structure in emission is lost and the red-shifted broad spectrum is observed (Figure 2). This shows a typical solvatochromism, indicating a strong ICT character of the emissive state relaxed in polar media. ${ }^{21}$ It is interesting that the $\lambda_{\mathrm{abs}}$ in water is $\sim 10 \mathrm{~nm}$ blue-shifted relative to that in DMSO for each fluorophore. The absorption maxima in
Table 1. Linear spectroscopic data in different solvents

\begin{tabular}{lccccc}
\hline & Solvent & $\lambda_{\text {abs }}(\mathrm{nm})$ & $\lambda_{\mathrm{PL}}(\mathrm{nm})$ & $\lambda_{\mathrm{FL}}-\lambda_{\text {abs }}(\mathrm{nm})$ & $\eta^{a}$ \\
\hline IN & Toluene & 434 & 486 & 52 & 0.92 \\
IN & THF & 436 & 496 & 60 & 0.86 \\
IN & DMSO & 446 & 536 & 90 & 0.75 \\
IC & DMSO & 445 & 535 & 90 & 0.58 \\
IC & $\mathrm{H}_{2} \mathrm{O}$ & 435 & 553 & 118 & 0.04 \\
\hline $\mathbf{2 N}$ & Toluene & 420 & 468 & 48 & 0.95 \\
$\mathbf{2 N}$ & THF & 419 & 470 & 51 & 0.87 \\
$\mathbf{2 N}$ & DMSO & 423 & 484 & 61 & 0.92 \\
$\mathbf{2 C}$ & DMSO & 422 & 483 & 61 & 0.81 \\
$\mathbf{2 C}$ & $\mathrm{H}_{2} \mathrm{O}$ & 410 & 505 & 95 & 0.42 \\
\hline $\mathbf{3 N}$ & Toluene & 441 & 492 & 51 & 0.92 \\
$\mathbf{3 N}$ & THF & 440 & 499 & 59 & 0.90 \\
$\mathbf{3 N}$ & DMSO & 443 & 533 & 90 & 0.87 \\
$\mathbf{3 C}$ & DMSO & 442 & 531 & 89 & 0.81 \\
$\mathbf{3 C}$ & $\mathrm{H}_{2} \mathrm{O}$ & 431 & 537 & 106 & 0.52 \\
\hline
\end{tabular}

QQuantum yield was measured relative to fluorescein in water at $\mathrm{pH}=\mathrm{ll}$.

DMSO (and in water) were measured at $445 \mathrm{~nm}(435 \mathrm{~nm}$ ) for $1 C$, at $422 \mathrm{~nm}(410 \mathrm{~nm})$ for $2 C$, and at $442 \mathrm{~nm}(431 \mathrm{~nm})$ for $\mathbf{3 C}$, respectively. The blue-shifted absorption in water can be attributed to different solubility and the resulting geometry change due to the hydrophobic nature of the conjugated molecular backbone, regardless of the charged ionic groups on the periphery. In addition, the chromophores, 1-3, have strong e-donating nitrogen atoms at the termini of the structures. It is also expected that the solvent interaction via hydrogen bonding in water can perturb the ground energy state, yielding a blue-shifted absorption. ${ }^{21.22}$

In toluene, $1 \mathbf{N}, \mathbf{2 N}$ and $\mathbf{3 N}$ have high $\eta$, in the range of 0.9 . It is very noticeable that a pronounced drop in $\eta$ is observed for $1 \mathrm{C}(0.04)$ and the $\eta$ values for $2 \mathrm{C}(0.42)$ and 3C (0.52) remain still high in water. The reduced $\eta$ or fluorescence quenching in highly polar medium such as water is related to a quenching associated with the strong ICT character of the excited state. ${ }^{23.24}$ Inspection of Table 1 shows that the Stokes shift in water (the energy spacing 


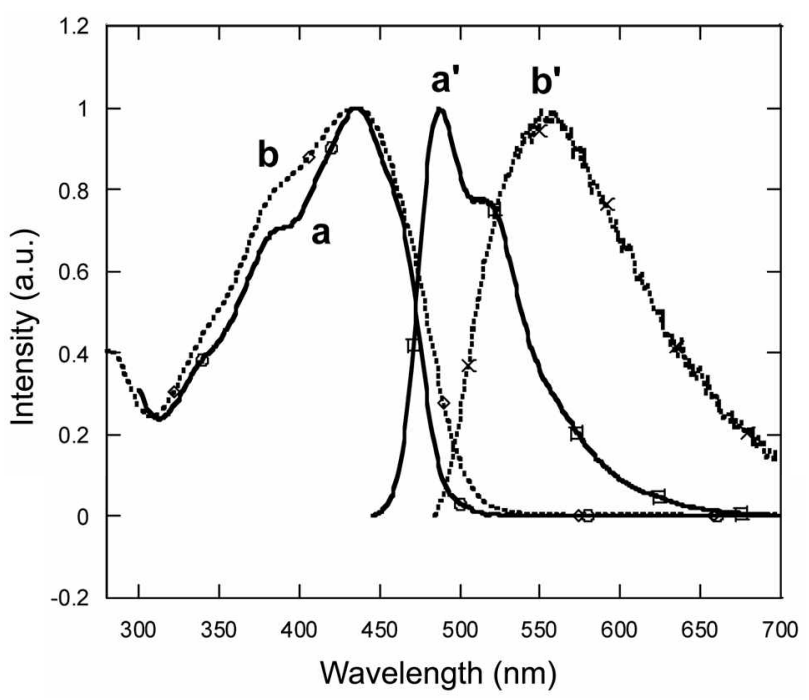

Figure 1. Normalized absorption and emission spectra of $1 \mathbf{N}$ in toluene $\left(a, a^{\prime}\right)$ and $1 \mathrm{C}$ in water $\left(b, b^{\prime}\right)$. Emission scans were collected by exciting at $\lambda_{\text {abs }}$ of each sainple.

between $\lambda_{\mathrm{abs}}$ and $\left.\lambda_{\mathrm{PL}}\right)$ is larger for $1 \mathrm{C}(118 \mathrm{~nm})$ than for the other chromophores, $2 \mathrm{C}$ and $\mathbf{3 C}(\sim 100 \mathrm{~nm})$. This suggests a larger geometry change in the molecule $\mathbf{~} \mathrm{C}$ in water from the ground state to the excited state owing to the strong ICT from the teminal dialkylamino group to the $\mathrm{pCp}$ core. It is observed that $\eta$ in water is inversely proportional to the donor strength of the terminal substituent group $(\mathbf{1}>\mathbf{2}>\mathbf{3})$. The donor strength order is consistent with the oxidation potential measured by cyclic voltammetry (CV). The measured electrochemical $\mathrm{E}_{\mathrm{M}_{1} / \mathrm{M}}$ is $-50 \mathrm{mV}$ for $1 \mathrm{~N}, 160 \mathrm{mV}$ for $2 \mathrm{~N}$ and $210 \mathrm{mV}$ for $3 \mathrm{~N}$ relative to ferrocene (Figure 3 ). $\mathrm{CV}$ was carried out in $0.1 \mathrm{M} n-\mathrm{Bu}_{4} \mathrm{NPF}_{6}$ in THF with a scan rate of $100 \mathrm{mV} / \mathrm{s}$. It suggests that weaker donors and enhanced $\pi$-conjugation are desirable for high $\eta$ in water.

As shown in Figure 4 and Table 1, we also note that in DMSO, there are no measurable differences in the linear UV/vis and PL spectroscopy for each neutral (N) and charged (C) pair of the structures. This solvent is of intermediate polarity between highly polar water and nonpolar toluene, and can dissolve both the neutral and ionic molecules. The charged end groups on the periphery for the solubility adjustment do not interact with the electronic structure of the chromophores.

Two-photon absorption spectroscopy. TPA properties were measured with the two-photon induced fluorescence (TPIF) measurement technique using femto-second laser pulses as described in the literature. ${ }^{70.10 a}$ The TPA maximum wavelength $\left(\lambda_{\text {TPA }}\right)$ and TPA cross section $(\delta)$ for $1 \mathrm{~N}$ in toluene ( $725 \mathrm{~nm}$ and $1290 \mathrm{GM}$, respectively) are similar to those previously reported for 4,7,12,15-tetra(4'-dihexylaminostyryl)-[2.2]paracyclophane (720 $\mathrm{nm}$ and $1410 \mathrm{GM}) .{ }^{20}$ In toluene, $\lambda_{\text {TPA }}$ is observed at $725 \mathrm{~nm}$ for $1 \mathrm{~N}$ and, at $700 \mathrm{~nm}$ for $2 \mathrm{~N}$ and at $770 \mathrm{~nm}$ for $3 \mathrm{~N}$. In the linear absorption, ise is $434 \mathrm{~nm}$ for $1 \mathrm{~N}, 420 \mathrm{~nm}$ for $2 \mathrm{~N}$ and $441 \mathrm{~nm}$ for $3 \mathrm{~N}$, respectively. As shown in Tables $I$ and 2 , the $\lambda_{\text {TPA }}$ for the pCp structures $(1 \mathrm{~N}-3 \mathrm{~N})$ follows the trend of $\lambda_{\mathrm{abs}} .3 \mathrm{~N}(1910$

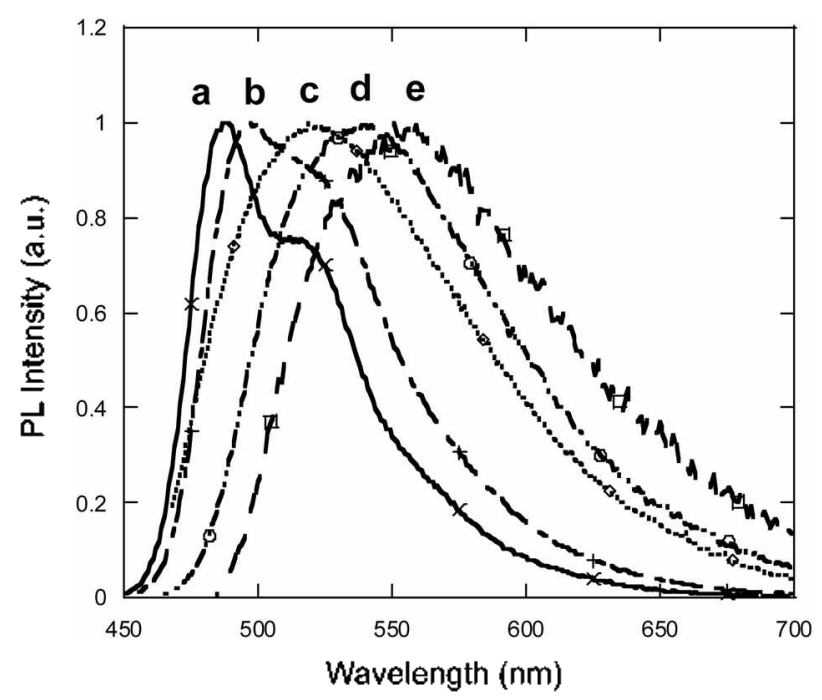

Figure 2. Enission spectra show a typical solvatochromism with increasing solvent polarity. $1 \mathrm{~N}$ in toluene (a) and in THF (b), 1C in methanol (c), in DMSO (d) and in water (e).

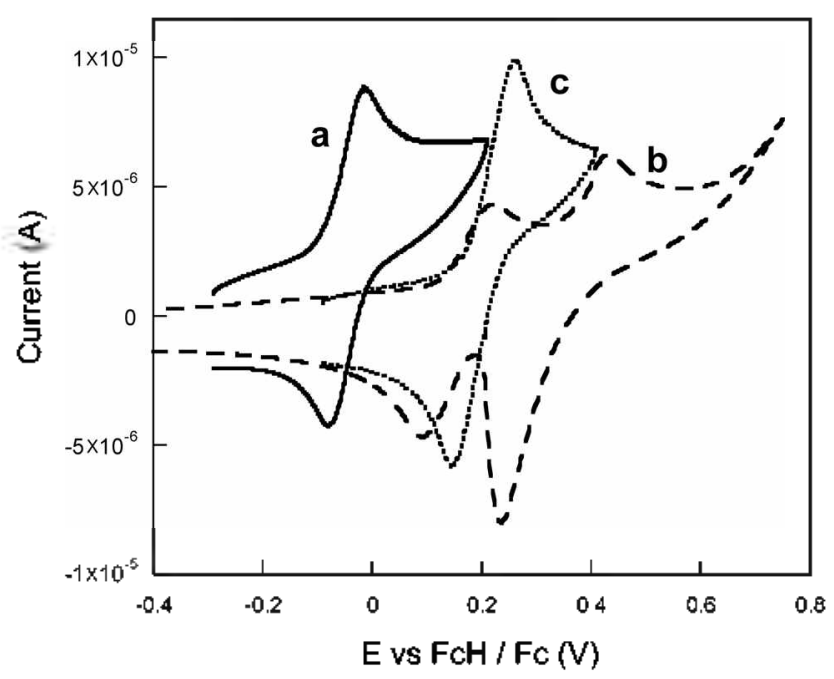

Figure 3. Cyclic voltamograms of $1 \mathrm{~N}$ (a), $2 \mathrm{~N}$ (b) and $3 \mathrm{~N}$ (c). CV

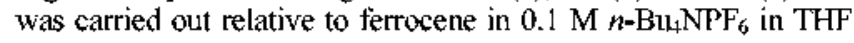
with a scan rate of $100 \mathrm{mV} / \mathrm{s}$.

GM in toluene) has higher $\delta$ relative to $1 \mathrm{~N}$ (1190 GM in toluene) and $2 \mathrm{~N}$ (1610 GM in toluene). Previous studies demonstrate that diarylamino donor groups can provide for larger or similar cross sections relative to their dialkylamino counterparts due to the enhanced $\pi$-conjugation. ${ }^{7}$

We investigated the TPA spectroscopy of $\mathbf{N}$ and $\mathbf{C}$ series in several solvents of substantially different polarity. Although the $\lambda_{\text {TPA }}$ follows the trend of $\lambda_{\text {aks }}$ and no significant change was observed in the band shape in different media, a clear solvent dependence of the measured $\delta$ value was observed. A similar trend for the solvent effect on TPA was measured with the DSB-based chromophores. ${ }^{8 c}$ The $\delta$ value in THF is 1.2-1.3 times larger than that in toluene for $2 \mathrm{~N}$ and $3 \mathrm{~N}$. For $1 \mathrm{~N}$, it is even 1.7 times larger than that in toluene. The TPA spectra of $\mathbf{3 N}$ and $\mathbf{3 C}$ in several solvents are presented in Figure 5. As the polarity of solvent is increased, 


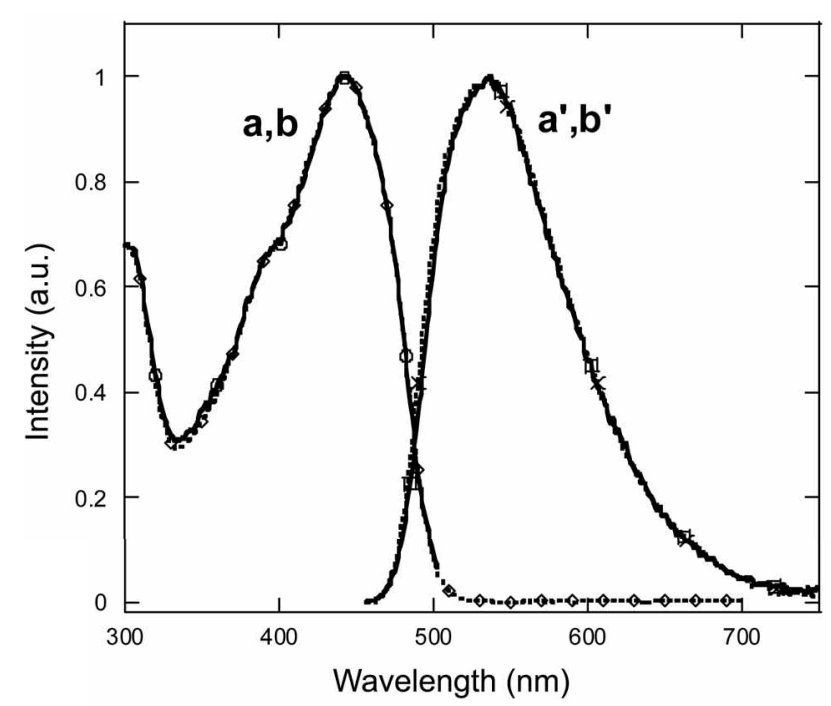

Figure 4. Normalized absorption and emission spectra of $3 N\left(a, a^{+}\right.$: solid line) and $3 \mathrm{C}(\mathrm{b}, \mathrm{b}$ : dotted line) in DMSO.

Table 2. TTA spectroscopic data in different solvents

\begin{tabular}{lccccc}
\hline & Solvent & $\lambda_{\text {TTA }}(\mathrm{nm})$ & $\delta^{*}(\mathrm{GM})$ & $\eta$ & $\eta \delta^{\text {h }}(\mathrm{GM})$ \\
\hline $\mathbf{1 N}$ & Toluene & 725 & 1290 & 0.92 & 1190 \\
$\mathbf{1 N}$ & THF & 725 & 2180 & 0.86 & 1870 \\
$\mathbf{1 N}$ & DMSO & 745 & 1260 & 0.75 & 950 \\
$\mathbf{1 C}$ & DMSO & 745 & 1360 & 0.58 & 790 \\
$\mathbf{1 C}$ & $\mathrm{H}_{2} \mathrm{O}$ & 725 & 370 & 0.04 & 15 \\
\hline $\mathbf{2 N}$ & Toluene & $\sim 700^{6}$ & 1690 & 0.95 & 1610 \\
$\mathbf{2 N}$ & THF & -700 & 1990 & 0.87 & 1730 \\
$\mathbf{2 N}$ & DMSO & -700 & 1380 & 0.92 & 1270 \\
$\mathbf{2 C}$ & DMSO & -700 & 1260 & 0.81 & 1020 \\
$\mathbf{2 C}$ & $\mathrm{H}_{2} \mathrm{O}$ & -700 & 700 & 0.42 & 290 \\
\hline 3N & Toluene & 770 & 2080 & 0.92 & 1910 \\
$\mathbf{3 N}$ & THF & 770 & 2690 & 0.90 & 2420 \\
3N & DMSO & 770 & 1670 & 0.87 & 1450 \\
3C & DMSO & 770 & 1530 & 0.81 & 1240 \\
3C & $\mathrm{H}_{2} \mathrm{O}$ & 750 & 690 & 0.52 & 360
\end{tabular}

TPA spectra were oblained by femto-second laser spectroscopy using fluorescein (in water, $\mathrm{pH}=11$ ) and 1.4-bis(2-melhylstyryl)benzene (in cyclohexane) as references $\left(\mathrm{GM}=10^{-50} \cdot \mathrm{cm}^{4} \cdot \mathrm{s}\right.$ photon $\left.{ }^{-1}\right)$. "TPA action cross section. "We could not measure the exact $\lambda \mathrm{TPA}$ due to lasser instability at the tuning wavelength around $700 \mathrm{~nm}$.

the TPA peak, $\delta_{\max }$ increases to a maximum point in THF, after which increasing the polarity causes a decrease of $\delta_{\max }$. This nonmonotonic solvent effect on TPA was previously predicted by several theoretical calculations. Kogej et al. studied the structure-property relationships for the donoracceptor stilbene derivative, 4-dimethylamino-4'-fornylstilbene, using quantum-chemical calculations at the semiempirical level..$^{93}$ The evolution of TPA was calculated as a function of the degree of ground state polarization by imposing an extemal field, directed such as to favor stabilization of ICT. In their calculation, the TPA peak $\left(\delta_{\max }\right)$ was observed at an intermediate value of the degree of $\mathrm{BOA}^{25}$ between the neutral structure and the cyanine limit. BOA can be consi-

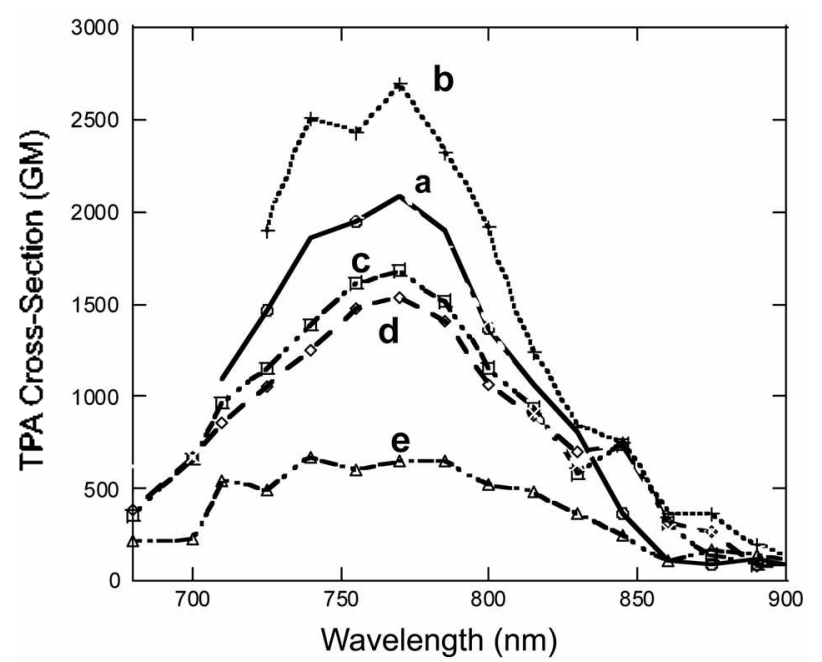

Figure 5. Two-photon absorption spectra of $3 \mathrm{~N}$ and $3 \mathrm{C}$ in different solvents. $3 \mathrm{~N}$ in toluene (a) and in THF (b), 3N and 3C in DMSO (c, d) and $3 \mathrm{C}$ in water (c).

dered as the ground state polarization in different media.

Another theoretical approach by Wang investigated the solvent effect on molecular geometry, electronic structure and the TPA of the typical D- $\pi-\mathrm{A}$ structure, $4-\operatorname{trans} s-[p-(\mathrm{N}, \mathrm{N}-$ dibutylamino)-p-stilbenylvinyl]pyridine. ${ }^{9 c}$ The $\delta$ value increases with respect to the solvent polarity and reaches a maximum at intermediate polarity of $\varepsilon=20.7$. A nonmonotonic behaviour of $\delta$ with regard to the solvent polarity was also calculated. It was suggested that the presence of solvent results in increase of charge separation in both ground and ICT excited states and that the electronic structure change by the solvent is the mechanism behind the increase of TPA. However, substantial uncertainties still remain on the exact role of solvents on modulating $\delta$ values and there is a disagreement among previous theoretical calculations. ${ }^{9}$

It is noticeable that the TPA measurements in water show a substantial decrease in $\delta$ for all cases, 1-3. One possible explanation is a specific solvent interaction via hydrogen bonding, which can strongly decrease the ICT from the amino donor units to the $\mathrm{pCp}$ core. The $\delta$ values of ionic structures $(\mathbf{1 C - 3 C})$ in water are about one-third relative to those in toluene $(\mathbf{1 N}-\mathbf{3 N})$. In particular, $1 \mathrm{C}$ with the strongest e-donor (among 1-3) of dialkylamino substituents shows a dramatic decrease of TPA action cross section ( $\eta \delta$ ) due to PL quenching related to strong ICT. However, $2 \mathrm{C}$ and $3 \mathrm{C}$ exhibit a moderate decrease of $\eta \delta$. As discussed earlier, the above data give us an insight into the molecular design for efficient TPM-tag with large $\eta \delta$ in aqueous medium. Moderate ICT and the extended conjugation are better means of obtaining an optimized product of $\eta$ and $\delta$ in water. In summary, the data in Table 2 imply that TPM imaging perfornance (which is proportional to $\eta \delta$ ) is strongly dependent on the environment around the fluorophore label. For example, the $\eta \delta$ of the TPM-tags in membrane or in intracellular fluid will be very different. The findings herein should be taken into consideration when examining TPM images where fluorescence intensities are used to gauge 
Table 3. Sumunary of time-resolved fluorescence spectroscopy

\begin{tabular}{|c|c|c|c|c|}
\hline & Solvent & $\tau_{12}(\mathrm{~ns})^{\varphi}$ & $\eta$ & $\tau_{\mathrm{j}}(\mathrm{ns})^{\beta}$ \\
\hline $1 N$ & Hexane & 1.4 & 0.7 & 2.0 \\
\hline $1 N$ & Toluene & 2.0 & 0.92 & 2.2 \\
\hline $1 N$ & THF & 2.0 & 0.86 & 2.3 \\
\hline $1 \mathrm{~N}$ & DMSO & 3.8 & 0.75 & 5.1 \\
\hline $1 \mathrm{C}$ & DMSO & 3.8 & 0.58 & 6.6 \\
\hline $1 \mathrm{C}$ & $\mathrm{H}_{2} \mathrm{O}$ & 0.5 & 0.04 & 12.5 \\
\hline $2 \mathrm{~N}$ & Toluene & 1.7 & 0.95 & 1.8 \\
\hline $2 \mathrm{~N}$ & THF & 2.1 & 0.87 & 2.4 \\
\hline $2 \mathrm{~N}$ & DMSO & 3 & 0.92 & 3.3 \\
\hline $2 C$ & DMSO & 2.5 & 0.81 & 3.1 \\
\hline $2 \mathrm{C}$ & $\mathrm{H}_{2} \mathrm{O}$ & 6.7 & 0.42 & 16.0 \\
\hline $3 N$ & Hexane & 1.4 & 0.90 & 1.6 \\
\hline $3 N$ & Toluene & 1.7 & 0.92 & 1.8 \\
\hline $3 N$ & THF & 2.0 & 0.90 & 2.2 \\
\hline $3 N$ & DMSO & 3.5 & 0.87 & 4.0 \\
\hline $3 \mathrm{C}$ & DMSO & 3.6 & 0.81 & 4.4 \\
\hline $3 \mathrm{C}$ & $\mathrm{H}_{2} \mathrm{O}$ & 7.3 & 0.52 & 14.0 \\
\hline
\end{tabular}

Measured PL lifetime. ${ }^{b}$ The intrinsic PL lifetime, $n$ was calculated using the formula of $\tau_{\mathrm{t}}=\tau_{\mathrm{m}} / \mathrm{t}$.

concentration of the labelled substrates in biological samples.

Time-resolved photoluminescence spectroscopy. Table 3 summarizes the time-resolved PL spectroscopy data obtained in several solvents of different polarity. PL intensity decay measurements can provide information complementary to the steady-state data and give insight into the excited state dynamics. Table 3 contains both the measured $\left(\tau_{m}\right)$ and the intrinsic (or natural) lifetime $\left(\tau_{i}\right)$ for each chromophore.

As described in several previous studies, ${ }^{14,15}$ the electronic structure of bichromophoric [2.2]paracyclophane compounds can be approximated and understood as a combination of two states: one that is similar to that of the parent DSB chromophore (TB) and the other which contains delocalization between the two monomers, largely localized on the [2.2]pCp core (TS). The TB abbreviation is used to highlight typical 'through-bond' $\pi$-conjugation, while TS refers to the 'through-space' delocalization across the transarnular gap. The PL data suggest that the emitting state of the $\mathrm{xpp}$ chromophore is a mixed one of TB and TS which gives rise to a delocalization over the entire molecule. As shown in
Table 3 , there is a clear progression toward longer $\tau_{1}\left(=\tau_{m} / \eta\right)$ values with increasing solvent polarity for 1-3. This peculiar property originates from the unique molecular structure of paracyclophane. This is particularly true in the highly polar medium of water, where the $\tau_{1}$ is $12.5 \mathrm{~ns}$ for $1 \mathrm{C}$, $16 \mathrm{~ns}$ for $2 \mathrm{C}$ and $14 \mathrm{~ns}$ for $\mathbf{3 C}$, respectively. This is substantially longer than those in organic solvents. It implies that there is a competition between TB and TS in the description of the final emitting state $\left(S_{1}\right)$ with changing solvent polarity. Increasing solvent polarity lowers the TS energy level to ensure its greater participation into $\mathrm{S}_{1}$, yielding the lower oscillator strength and increased PL lifetime (Scheme 3). It follows that the TS state created by electron exchange across the $\mathrm{pCp}$ core is susceptible to solvent polarity due to a polarizable electronic structure. ${ }^{15}$

This interesting and unique solvent dependence of the PL lifetime of paracyclophene fluorophores is useful in probing the substrate in biological samples. A combination of fluorescence imaging and the two-photon induced PL lifetime measurement during TPM imaging can be very powerful when studying biological processes. Both the large TPA action cross section and clear solvent dependence of the PL lifetime indicate the great potential of paracyclophane-based fluorophores for the molecular labels in TPM biological imaging.

\section{Conclusions}

In summary, we report the molecular design, linear- and nonlinear TPA spectroscopic characterizations of [2.2]paracyclophane-based two-photon fluorophores. Neutral and cationic structures with the same electronic conjugation allow us to study nonmonotonic solvent effects on the TPA cross section $(\delta)$ and action cross section $(\eta \delta)$. It indicates that great care should be taken when examining TPM images where fluorescence intensities are used to gauge concentration of the labelled substrate in biological samples. The specific solvent dependence of the PL lifetime of the unique paracyclophane structure is able to play an important role in probing the polarity of the substrate in biological cells. A combined measurement of the two-photon induced PL intensity and the PL lifetime during TPM imaging using the paracyclophane fluorophores as molecular-tags can be very powerful in understanding biological processes.

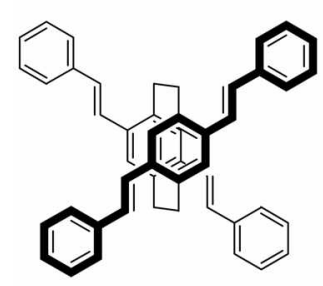

TB

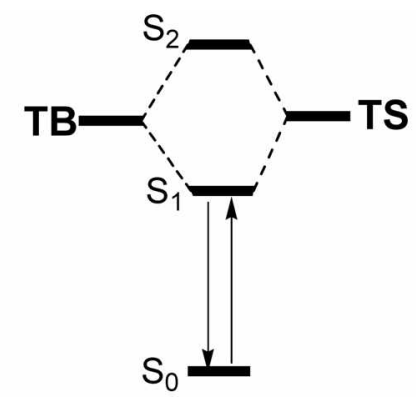

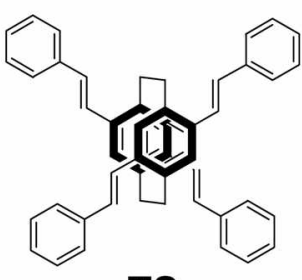

TS

Scheme 3. Qualitative description of the emissive state resulted from inixing TB and TS states of the paracyelophane structure. 


\section{Experimental Section}

Aniline was freshly purified by vacuum distillation. All other commercial chemicals were purchased from Aldrich and used as received. ' $\mathrm{H}$ - and ${ }^{13} \mathrm{C}-\mathrm{NMR}$ spectra were collected on a Varian Unity $400 \mathrm{MHz}$ (or $200 \mathrm{MHz}$ ) spectrometer. Mass spectrometry analyses were performed by UC, Santa Barbara, Mass Spectrometry Laboratory. The UV/vis absorption spectra were recorded on a Shimadzu UV-2401 PC diode array spectrometer. Photoluminescence spectra were obtained on a PTI Quantum Master fluorometer equipped with a Xenon lamp excitation source. Fluorescent lifetime in different solvents was measured on a PTI Quantum Master fluorometer equipped with a Hydrogen flash lamp (pulse width $<1 \mathrm{~ns}$ ). Instrument responses were measured using the signal generated by a non-luminescent scattering sample at the same excitation wavelength. In case that the lifetime is less than $1 \mathrm{~ns}$, a time-correlated single-photon counting technique (TCSPC) ${ }^{26}$ was also used to verify the measurement using Hydrogen flash lamp.

TPA spectra of the compounds studied were measured using two-photon induced fluorescence spectroscopy. ${ }^{70.100}$ The radiation dispersed by the spectrometer was detected by a thermoelectrically cooled charge coupled device (CCD) camera (Roper Scientific Spec10:100B/TE). Excitation pulses with typical duration $90 \mathrm{fs}$ and energy of $-6 \mathrm{~nJ}$ within the spectral range $700-1000 \mathrm{~nm}$ were produced by the modelocked laser (Spectraphysics Tsunami) with a repetition rate of $82 \mathrm{MHz}$. For the spectral range $620-700 \mathrm{~nm}$, a femtosecond optical parametric amplifier (OPA) was used. Signal output from the OPA (Spectraphysics OPA-800C) was upconverted into the visible range of spectrum using the second harmonic generation (SHG) process in $\beta$-barium borate crystal, which yielded $\sim 120$ fs pulses with an energy of $-30 \mu \mathrm{J}$ and a repetition rate of $1 \mathrm{kHz}$. Neutral density filter wheel was used to attenuate the energy of the laser pulses down to the desirable level.

In all measurements, the concentration of the sample was adjusted around $10^{-5} \mathrm{M}$, in order to avoid self-quenching of the emission. Fluorescence quantum yields were measured relative to fluorescein and verified using the referenceless technique described previously. ${ }^{27}$ After being properly degassed, our samples did not exhibit any sign of degradation within the scope of the experiment.

As the reference materials for TPA measurements in the spectral range of $700-900 \mathrm{~nm}$, we used three laser dyes: Fluorescein (purchased from Acros Inc.), Coumarin 503 (aka Coumarin 307, purchased from Exciton Inc.) and Rhodamine 610 (aka Rhodamine B, purchased from Exciton Inc.). The TPA values relative to the standard of fluorescein were verified using the other references of coumarin and rhodamine. The measured $\delta$ values using three different references are in good agreement in the experimental error range $(\sim 15 \%)$. Fluorescein was prepared in water at $\mathrm{pH}=11$. Coumarin 503 and Rhodamine 610 were dissolved in methanol and $p$-bis( $\alpha$-methylstyryl)benzene in cyclohexane was used as a reference for measurements in the spectral range below $700 \mathrm{~nm}^{28}$

Acknowledgements. This work was supported by the Korea Research Foundation Grant funded by the Korean Government (MOEHRD, Basic Research Promotion Fund) (KRF-2006-331-D00139).

\section{References}

I. Goppert-Mayer, M. Anw. Phys, 1931, 9, 273.

2. (a) Kaiser, W.; Gartet, C. G B. Phys, Rev. Lett, 1961, 7, 229. (b) Rentzepis, P. M.; Pao, Y. H. Appl. Phys. Lett. 1964, 5, 156. (c) Peticolas, W. L. Annu. Rev. Phys. Chent 1967, 18, 233.

3. (a) Cumpston, B. H.; Anathavel, S. P.; Barlow, S.; Dyer, D. L.; Ehrlich. J. E.; Erskine, L. L.; Heikal, A. A.; Kuebler, S. M.; Lee, I.-Y.; McCord-Maughon, D.; Qin, J.; Röckel, H.; Rumi, M.; Wu, X.-L.; Marder, S. R.; Perry, J. W, Nature 1999, 398 , 5I. (b) Park, \$. H.; Lim, T. W.; Yang, D.-Y.; Kong, H. J.; Kim, R.-H.; Kim, K.S.; Lee, K.-S. Bull. Korean Chen. Soc. 2004, 25, 1119.

4. (a) Denk, W.; Strickler, J. H.; Webb, W. W. Science 1990, 248, 73. (b) Köhler, R. H.; Cao, J.; Zipfel, W. R.; Webb, W. W.; Hansen, M. R. Science 1997, 276, 2039.

5. Zipfel, W. R.; Williams, R. M.; Webb, W. W. Nat. Biotechol. $2003,21,1369$.

6. Albota, M.; Beljonne, D.; Brédas, J.-L.; Ehrlich, J. E.; Fu, J.-Y.; Heikal, A. A.; Hess, S. E.; Kogei, T.; Levin, M. D.; Marder, S. R.; McCord-Maughon, D.; Perry, J. W.; Röckel, H.; Rumi, M.; Subramaniam, G.; Webb, W. W.; Wu, X.-L.; Xu, C. Science 1998, 281,1653

7. (a) Rumi, M.; Ehrlich, J. E.; Heikal, A. A.; Perry, J. W.; Barlow, S.; Hu, Z.; McCord-Maughon, D.; Parker, T. C.; Röckel, H.; Thayumanavan, S.; Marder, S. R.; Beljonne, D.; Brédas, J.-L. J. An. Chem. Soc. 2000, 122, 9500. (b) Cho, B. R.; Son, K. H.; Lee, S. H.; Song. Y.-S.; Lee, Y.-K.; Jeon, S.-J.; Choi, J. H.; Lee, H.; Cho, M. J. Am. Chem. Soc, 2001, 123, 10039.

8. (a) Woo, H. Y.; Hong, J. W; Liu, B.; Mikhailovsky, A.; Korystov, D.; Bazan, G. C.J. Am. Chem. Soc. 2005, 127, 820. (b) Woo, H. Y.; Korystov, D.; Mikhailovsky, A.; Nguyen, T.-Q.; Bazan, G. C. J. Ant Chem. Soc. 2005, 127, 13794. (c) Woo, H. Y; Liu, B; Kohler, B.; Korystov, D.; Mikhailovsky, A.; Bazan, G. C. J. Ant. Chem, Soc. 2005, 127, 14721 .

9. (a) Kogej, T.; Beljonne, D.; Meyers, F.; Perry, J. W.; Marder, S. R.; Brédas, J.-L. Chem. Phys. Lett, 1998, 298, I. (b) Luo, Y.; Noman, P.; Macak, P.; Ågren, H. J. Phys. Chent. A 2000, 104, 4718. (c) Wang, C.-K.; Zhao, K.; Su, Y.; Ren, Y.; Zhao, X.; Luo, Y. J. Chem. Phys. 2003, 110, 1208. (d) Zalesny, R.; Bartkowiak, W. Styrcz, S.; Leszczynski, J. J. Phys. Chem. A 2002, $106,4032$.

10. (a) Xu, C., Webb, W. W. J. Opt. Soc. Am. B 1996, 13, 481. (b) Xu, C.; Zipfel, W.; Shear, J. B.; Williams, R. M.; Webb, W. W. Proc. Natl. Acad. Sci. USA 1996, 93, 10763.

I1. (a) Bazan, G. C.; Oldham Jr., W. J.; Lachicotte, R. J.; Tretiak, S.; Chemyak, V.; Mukamel, S. J. Ani. Chem. Soc 1998, I20,9188. (b) Zyss, J.; Ledoux, I.; Volkov, S.; Chernyak, V.; Mukamel, S.; Bartholomew, G. P.; Bazan, G. C. J. Am. Chem. Soc. 2000, 122, 11956 .

12. (a) Gilbert, A.; Baggot, J. Essentials of Molectlor Photochenistry; Blackwell Scientific Publications: Oxford, 1991. (b) Pope, M.; Swenberg. C. E. Electronic Processes in Organic Crystals; Oxford University Press: Oxford, 1982.

13. (a) Morisaki, Y,; Chujo, Y. Macromolecties 2002, 35, 587, (b) Wang, W.; Xu, J.; Lai, Y.-H. Org. Lett, 2003, 5, 2765. (c) Hwang I.-W.; Aratani, N.; Osuka, A.; Kim, D. Bull. Korean Chent. Soc. 2005. 26. 19.

14. (a) Hong, J. W.; Gaylord, B. S.; Bazan, G. C. J. Ant Chent Soc 2002, 124, 11868 . (b) Hong, J. W.; Hadjar, B.; Bazan, G. C. Chem. Eur, J. 2003, 9, 3186.

15. Hong, J. W.; Woo, H. Y.; Liu, B.; Bazan, G. C. J. Am. Chem, Soc, 
$2005,127,7435$.

16. (a) Bartholomew, G P.; Bazan, G C. J. Ant. Chem. Soc. 2002, I24, 51 83. (b) Bartholomew, G. P.; Bazan, G. C. Sitnhesis 2002, 9, 1245.

17. Moon, K.-J.; Shim, H.-K.; Lee, K.-S.; Zieba, J.; Prasad, P. N. Macromolecules 1996, 29, 861 .

18. Lee, H. J.; Sohn, J.; Hwang, J.; Park, S. Y.; Choi, H.; Cha, M. Chem. Mater. 2004, 16,456

19. The terminal iodide group is very labile to be eliminated in the presence of strong base, $t=\mathrm{BuOK}$ even at $0^{\circ} \mathrm{C}$. It was confirmed by 'H NMR that $\mathrm{I}$ or 2 iodides per molecule were removed during the reaction $\left(\mathrm{R}-\mathrm{CH}_{2} \mathrm{CH}_{2} \mathrm{I}+t-\mathrm{BuOK} \rightarrow \mathrm{R}-\mathrm{CH}=\mathrm{CH}_{2}\right.$ ).

20. (a) Bartholomew, G P.; Ledoux, I.; Mukamel, S.; Bazan, G. C.; Zyss, J. J. Am. Chem. Soc. 2002, 124, 13480. (b) Bartholomew, G. P.; Rumi, M.; Pond, S. J. K.; Perry, J. W.; Tretiak, S.; Bazan, G. C. J. Am. Chem. Soc. 2004, 126, 11529.

21. (a) Fayed, T. A. J. Photochem. Photobiol. A Chem. 1999, 121, 17. (b) Mongin, O.; Porrés, L.; Moreaux, L.; Mertz, J.; Blanchard-
Desce, M. Org. Lett. 2002, 4, 719. (c) Sarker, A. M.; Strehımel, B.; Neckers, D. C. Macromolecules 1999, 32, 7409.

22. Halpern, A. M.; Ruggles, C. J.; Zhang, X. J. Ant. Chen. Soc. $1987,109,3748$.

23. (a) Strehmel, B.; Sarker, A. M.; Malpert, J. H.; Strehmel, V; Seifert, H.; Neckers, D. C.J. Am. Chem. Soc. 1999, 121, 1226. (b) Jager, W. F.; Volkers, A. A.; Neckers, D. C. Macronolectles $1995,28,8153$.

24. Schuddeboom, W.; Jonker, S. A.; Warman, J. M.; Leinhos, U.; Kühnle, W.; Zachariasse, K. W. J. Phys. Chem, 1992, 96, 10809.

25 . p-bond order alternation within the vinylene segment.

26. O'Connor, D. V.; Phillips, D. Time Correlated Single Photon Counting; Academic Press: London, U. K., 1984.

27. Greenham, N. C.; Samuel, I. D. W.; Hayes, G. R.; Phillips, R. T.; Kessener, Y. A. R. R.; Moratti, S. C.; Holmes, A. B.; Friend, R. H. Chem. Phys, Lett. 1995, 24l, 89.

28. Kennedy, S. M.; Lylle, F. E. Anal. Chem 1986, 58, 2643. 